International Journal of Oceans and Oceanography

ISSN 0973-2667 Volume 14, Number 1 (2020), pp. 157-167

(C) Research India Publications

https://dx.doi.org/10.37622/IJoo/14.1.2020.157-167

\title{
Field and satellite observations on the seasonal variability of the surface chlorophyll- $a$ in the Bay of La Paz, Gulf of California, Mexico
}

\author{
Elizabeth Durán-Campos ${ }^{1}$, María Adela Monreal-Gómez², \\ David Alberto Salas de León ${ }^{2}$ and Erik Coria-Monter ${ }^{2 *}$ \\ ${ }^{1}$ Mazatlán Academic Unit. Institute of Marine Sciences and Limnology. National \\ Autonomous University of Mexico (UNAM). Cap. Joel Montes Camarena, Cerro del \\ Vigía, 82040, Mazatlán, Sinaloa, Mexico. \\ ${ }^{2}$ Ecology and Aquatic Biodiversity Unit. Institute of Marine Sciences and Limnology. \\ National Autonomous University of Mexico (UNAM). Av. Universidad 3000, Copilco, \\ Coyoacán, 04510, Mexico City, Mexico. \\ * Corresponding author: Erik Coria-Monter
}

\begin{abstract}
As the pigment present in all photosynthetic phytoplankton species, chlorophyll- $a$ (CHLA) is the most common indicator of the phytoplankton biomass in any aquatic ecosystem, and thus the quantification of its seasonal variability is key to understanding the dynamics of the marine ecosystem. Based on in-situ observations systematically gathered during four seasons in different years, this paper reports the surface CHLA concentrations in the central part of the Bay of La Paz, Gulf of California, Mexico. The in-situ data are compared and supported by satellite observations at $1 \mathrm{~km} /$ pixel of resolution from the Moderate Resolution Imaging Spectroradiometer. The results show clear seasonal variability, with the highest values recorded during winter time, while the lowest values were recorded during summer. Spring and fall represented seasons of transition. Satellite observations were consistent with the variability observed in in-situ data. The seasonal variability observed could be related to different mechanisms including the local atmospheric forcing, which induces wind-driven mixing and changes in the heating/cooling of the water column. The results presented here contribute to our understanding of the phytoplankton population dynamics in the Bay of $\mathrm{La} \mathrm{Paz}$, a highly productive region that supports different species with great importance both ecologically and economically.
\end{abstract}

Keywords: chlorophyll- $a$, seasonal variability, Bay of La Paz, Gulf of California 


\section{INTRODUCTION}

Chlorophyll- $a$ (CHLA) is the most abundant pigment on Earth, is a key component of the climate carbon system, and as the pigment present in all photosynthetic phytoplankton species, is the most common indicator of the phytoplankton biomass in any aquatic ecosystem [1,2]. Thus, quantification of its seasonal variability is key to understanding the dynamics of the marine ecosystem, particularly in coastal areas, as these sites are areas for refuge, feeding and spawning for several ecologically and commercially important species [3], predominantly in regions that have been characterized as hot-spots of biodiversity [4].

The Gulf of California and adjacent areas are unique and highly productive ecosystems that support an immense biodiversity, including endemic, endangered, threatened and protected species [5]. The Bay of La Paz is the largest basin within the gulf, and is one of the most important coastal regimes as it represents an environment of great biodiversity and productivity that supports an abundant variety of megafauna [6]. Additionally, because of its location, near the connection with the open Pacific Ocean, the bay represents a sensitive recorder of regional variations in the subtropical Pacific Ocean [7], the major source of interannual variability in the area being related to the El Niño/Southern Oscillation [8]. At the center of the Bay of La Paz there is a marginal basin with a maximum depth of $420 \mathrm{~m}$ named the Alfonso Basin, which has been classified as a slope basin produced by extensional tectonics in a borderland type margin setting [9]. This region has been characterized as highly dynamic, mainly due to the confluence of oceanographic processes that are present inside the basin at different scales and induce mixing within the water column and enhance the nutrient concentration in the euphotic layer, thus inducing high levels of CHLA. This process involves internal waves [10] and mesoscale cyclonic eddies [11], which in turn regulate the biological productivity in the region, particularly that of phytoplankton.

In the Bay of La Paz, CHLA variability has been associated with normal periods of surface layer heating and cooling, which in turn determine the mixed layer and the availability of nutrients that promote a high phytoplankton biomass [12]. Based on insitu observations, the seasonal variability of CHLA in the Bay of La Paz was evaluated by Martínez-López et al. [13], who linked the physical forcing with the CHLA concentration, showing an inverse relationship with temperature and water column transparency; the lowest values were found during the warmest season as a result of strong water stratification while the highest values were observed during the coldest season as a result of mixing processes in the water column. Reyes-Salinas et al. [14] documented the effect of water column stratification during summer, calculated using the stratification index, showing inhibition of the fertilization of the surface layers and thus primary productivity levels, which partially explains the seasonal variability in the Bay of La Paz.

Recent information suggests that the most conspicuous process within the bay that regulates biological production is the presence of a mesoscale cyclonic eddy that has been documented throughout the year and is assumed to be quasipermanent. This eddy has been associated with the generation of an Ekman nutrient pump that induces a high 
nutrient injection (particularly nitrate) and enhances the CHLA levels in the euphotic layer [11], which in turn lead to the differential distribution of diatoms and dinoflagellates [15], and a zooplankton aggregation in the eddy field [16].

This paper reports changes in the surface CHLA concentration in the central portion of the Bay of La Paz, based on in-situ observations gathered on board the research vessel (R/V) "El Puma" owned by the National Autonomous University of Mexico, during four scientific expeditions covering the winter, spring, summer and fall seasons. The results obtained from the in-situ observations are compared and supported by satellite data obtained from the Moderate Resolution Imaging Spectroradiometer (MODIS), coinciding with the dates when the research cruises took place. The results contribute to our understanding of the dynamics, in terms of the seasonal variability of phytoplankton biomass, of the Bay of La Paz, a highly productive region that supports different species with great importance both ecologically and economically.

\section{MATERIAL AND METHODS}

\section{Study area}

The Bay of La Paz is located in the southern part of the Gulf of California, close to its connection ( $200 \mathrm{~km})$ with the open Pacific Ocean. It is the largest basin in the gulf, covering an area of $\sim 3400 \mathrm{~km}^{2}$. The bay and the gulf are connected through two openings, with different dynamics; in the north, the Boca Grande is the main source of exchange for surface waters between the gulf and the bay because it is wide and deep, while in the southern part of the bay, the San Lorenzo channel joins the bay to the gulf through a shallow and narrow opening. The bay reaches its maximum depth $(420 \mathrm{~m})$ in the central area, in a marginal basin named the Alfonso Basin, which is highly dynamic due to the oceanographic processes that occur there, including internal waves and the presence of a quasipermanent cyclonic eddy [10,11]. This region is also highly dynamic in terms of its seasonal pattern of winds, with the prevalence of high velocity $\left(>10 \mathrm{~m} \mathrm{~s}^{-1}\right)$ and persistent northwesterly winds during the winter, and the occurrence of low wind speed conditions $\left(<5 \mathrm{~m} \mathrm{~s}^{-1}\right)$ associated with frequent calm periods during the summer [17]. This high variability in the wind pattern has been associated with different mixing processes that occur in the bay, and that ensure the availability of nutrients for the phytoplankton communities [4, 11]. The contribution of rivers to the bay is practically nil, which gives it the characteristics of an open ocean environment.

\section{Sampling strategy}

In this research a total of 20 hydrographic stations were systematically sampled in four oceanographic expeditions on board the R/V "El Puma" during four different seasons in different years (Figure 1). The hydrographic stations were selected by considering that the central portion of the bay, in the Alfonso Basin, is the region with the highest hydrodynamics in the Bay of La Paz, therefore making it of special scientific interest. The information used in this paper was collected during the following scientific expeditions: 1) "DIPAL-V", which took place in the winter of 2012 (December 9-12, 
2012); 2) "DIPAL-IV", which took place in the spring of 2011 (May 26-29, 2011); 3) "DIPAL-III", which took place in the summer of 2009 (August 12-16, 2009) and 4)

"PALEOMAR-I", which took place in the fall of 2014 (November 22-25, 2014).

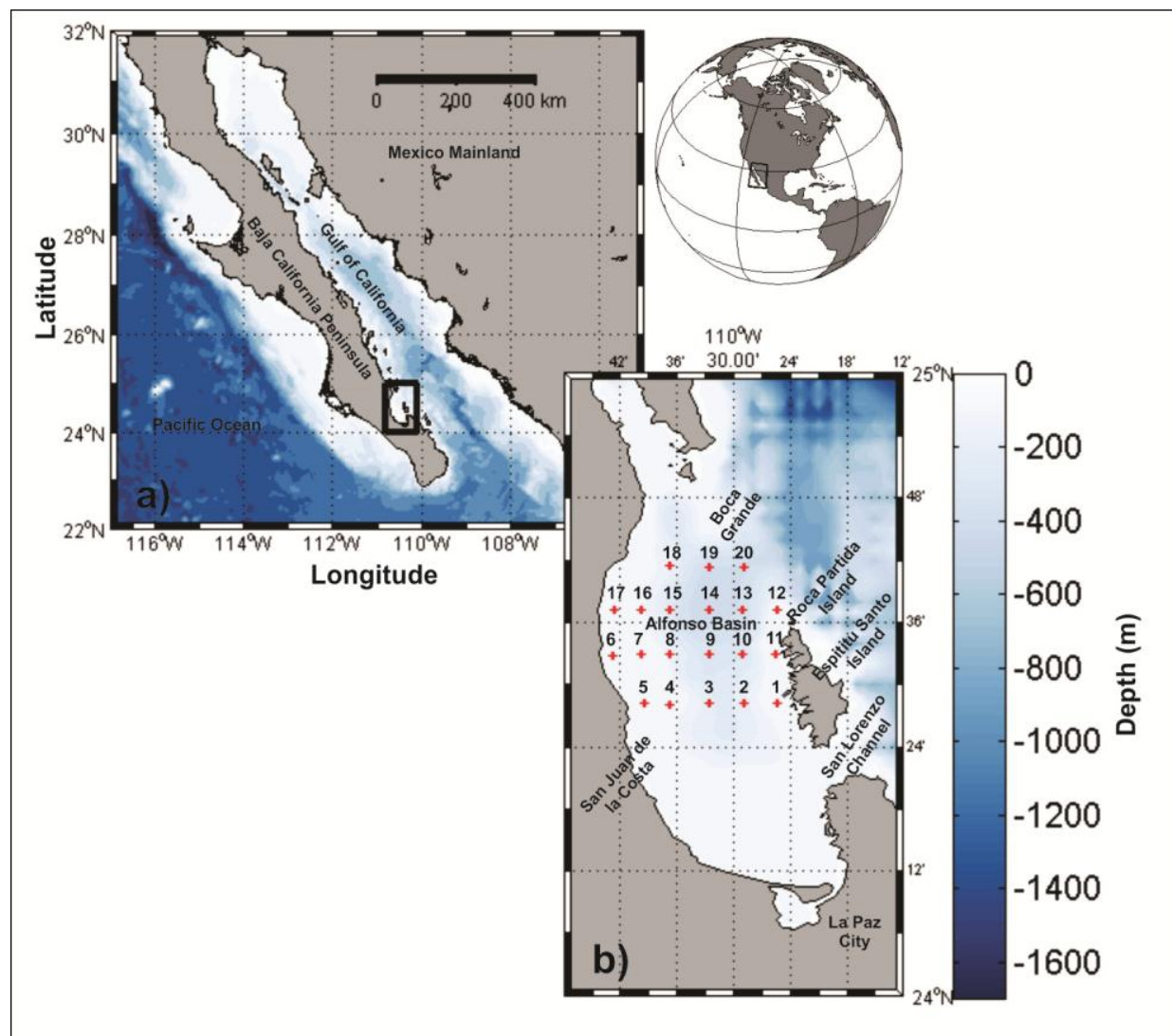

Figure 1. Location of the study area, a) The Gulf of California, and b) The Bay of La Paz. + symbols in red represent the hydrographic stations. The bathymetry is shown in meters.

At all hydrographic stations, a General Oceanics rosette equipped with 10 L Niskin bottles was used to collect water at the surface $(2 \mathrm{~m}$ depth) for spectrophotometric determinations of CHLA. Immediately after collection, sub-samples of $\approx 3 \mathrm{~L}$ were vacuum filtered with a stainless steel vacuum manifold system at less than 10 psi, through nitrocellulose membrane filters (Merck Millipore Company, MA, USA), with a pore size of $0.45 \mu \mathrm{m}$ and $47 \mathrm{~mm}$ in diameter. After filtration, the filters were deposited in plastic centrifuge tubes (covered with aluminum foil to avoid the negative effects of light) and then stored in dark conditions at $-20{ }^{\circ} \mathrm{C}$ prior to processing. During the filtering process, precautions were taken on board to work in low light conditions to prevent any possible degradation of the samples. 


\section{Laboratory analyses}

The samples were analyzed in the laboratory immediately after the research cruise. The CHLA was extracted with $90 \%$ acetone for $24 \mathrm{~h}$ in dark conditions and frozen at $-20{ }^{\circ} \mathrm{C}$ $[18,19]$. Following extraction, the samples were centrifuged at $4500 \mathrm{rpm}$ (Eppendorf centrifuge 5840) for $30 \mathrm{~min}$, then three measurements of absorbance were taken, following the protocols of Strickland and Parsons [18], at 750, 664, 647, and $630 \mathrm{~nm}$ using a Genesys 10S UV-VIS (Thermo Scientific) spectrophotometer. During the analyses, the measurements were taken while maintaining low light conditions in the laboratory to prevent degradation of the samples.

\section{Satellite images}

Satellite images of CHLA during the dates when the research cruises took place were obtained from MODIS of the NASA Ocean Color Browser (https://oceancolor.gsfc.nasa.gov/cgi/browse.pl). The images, with a spatial resolution of $1 \mathrm{~km} / \mathrm{pixel}$, were processed using SeaDAS version 7.4 following standard algorithms, and applying filters to remove low quality data. Before mapping, different filters were applied including CLDICE, HILT, LAND, and STRAYLIGHT.

\section{RESULTS AND DISCUSSION}

The CHLA levels obtained in the in-situ determinations showed interesting variations with progressive changes according to each season. The highest CHLA concentrations were recorded in the winter, ranging from 0.30 to $9.87 \mathrm{mg} \mathrm{m}^{-3}$ with the maximum values observed into a core in the region close to Roca Partida Island (Figure 2a). During spring the CHLA values ranged from 0.13 to $3.18 \mathrm{mg} \mathrm{m}^{-3}$, with the maximum values located in the same region as observed in winter (Figure $2 \mathrm{~b}$ ). The lowest values were recorded in the summer, with a maximum of just $1.17 \mathrm{mg} \mathrm{m}^{-3}$, and a homogeneous distribution throughout the study area (Figure 2c). During the fall, the CHLA values showed an incremental increase with respect to the summer, ranging from 0.04 to 2.60 $\mathrm{mg} \mathrm{m}^{-3}$ and with the maximum values in the central part of the study area (Figure $2 \mathrm{~d}$ ).

The Bay of La Paz and adjacent areas are characterized by low cloud conditions throughout the year, making it an interesting region for analyzing seasonal variations of CHLA derived from satellite imaging [20]. In this study, the satellite data obtained showed a clear signal due to the cloud-free conditions, with variations for each season supporting the in-situ observations, and although there were differences in their absolute values, it is important to keep in mind that there is natural variation between the extracted CHLA concentration and the data derived from satellite images due to changes in the quantum yield of phytoplankton [20]. 


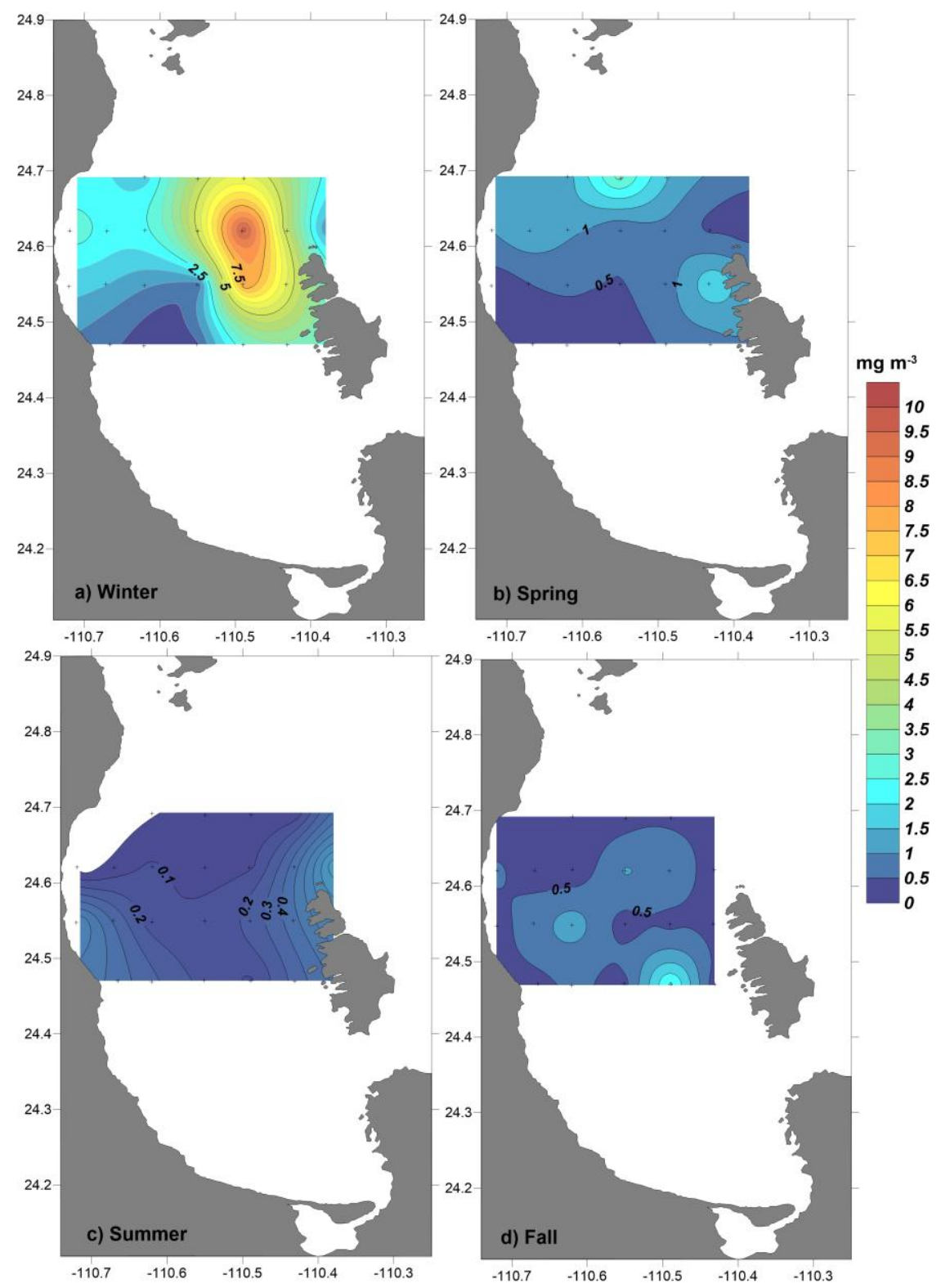

Figure 2. Surface CHLA distribution in the central part of the Bay of La Paz during four different seasons, a) winter, b) spring, c) summer, and d) fall.

The satellite observations showed that the highest values for the four target seasons in this study were recorded during the winter, reaching values of $10 \mathrm{mg} \mathrm{m}^{-3}$ in the western part of the bay, close to the coast (Figure 3a). This high concentration could be related to the presence of the mining industry active in San Juan de la Costa, which could represent a source of nutrients, particularly phosphate. The values observed in spring were lower than those observed in winter, ranging from 0.20 to $1.40 \mathrm{mg} \mathrm{m}^{-3}$ (Figure $3 \mathrm{~b}$ ). The lowest values of CHLA were observed in the summer, reaching only $0.30 \mathrm{mg}$ $\mathrm{m}^{-3}$ (Figure 3c). During the fall season, the values of CHLA showed an increase with 
respect to those observed in the summer, reaching values of $\sim 2.00 \mathrm{mg} \mathrm{m}^{-3}$ in the central part of the bay (Figure 3d).

The strong variability observed in the CHLA values in the different seasons sampled in this study, with maximum values during winter and minimum during summer, suggest that there are several physical mechanisms acting on the phytoplankton communities inside the Bay of La Paz throughout the year. One of these could be related to the wind patterns reported in the study area. During the winter, strong and persistent winds induce strong mixing within the water column, which ensures high nutrient concentrations in the euphotic layer available for the phytoplankton where the highest values of CHLA were observed. In contrast, during the summer the low wind speed conditions associated with frequent calm periods inhibit mixing of the water column, and thus there are no nutrient fluxes in the euphotic layer, leading to the lowest values of CHLA [12].

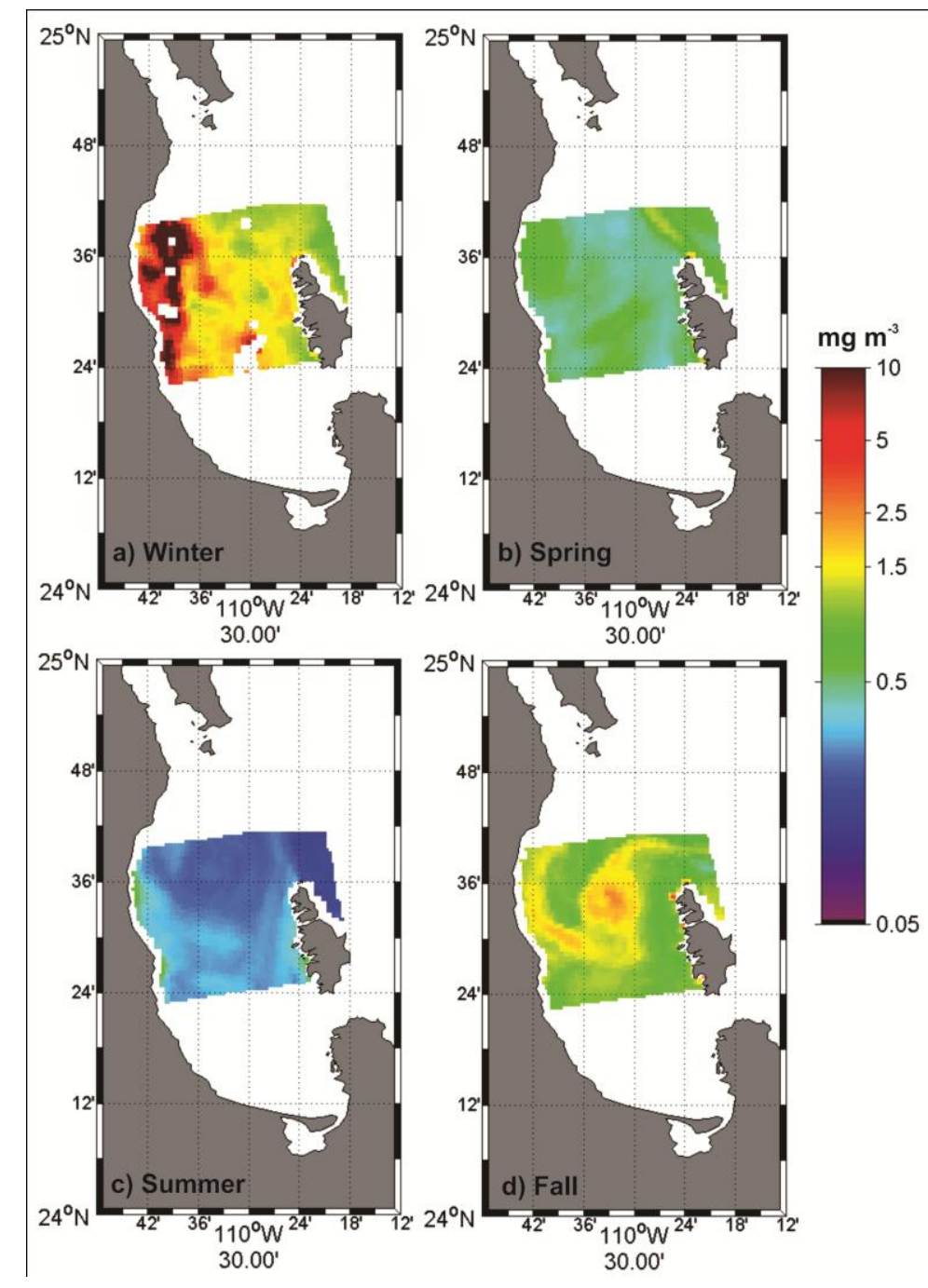

Figure 3. Satellite CHLA distribution in the central part of the Bay of La Paz during four different seasons, a) winter, b) spring, c) summer, and d) fall. 
Another mechanism that could be involved in determining the observed seasonal variability in the levels of CHLA is related to the heating and cooling of the surface layer throughout the annual cycle. Indeed, during the summer the maximum irradiance levels induce high values in the sea surface temperature, which results in strong stratification of the water column. This inhibits the flux of nutrients to the euphotic zone, prompting the formation of a warm and oligotrophic surface layer, which in turn explains the low CHLA concentrations observed. During the winter, the surface layer begins to cool due to changes associated with irradiance levels. This heat loss induces convective vertical movements, which in turn generate mixing in the water column and therefore ensure a suitable nutrient concentration for phytoplankton, leading to high CHLA values [21, 22]. Under this scenario, heat loss and convective vertical movements associated with the presence of strong winds would generate intense mixing in the water column, which explains the high concentrations of CHLA observed during the winter.

Seasonal variabilities in CHLA levels have been documented in different domains worldwide in agreement with our results. In the Mid-Atlantic Bight two major periods of high CHLA have been reported i.e., fall-winter and spring, associated with the occurrence of storms that induced mixing of the water column [23]. Off the western coast of Sabah (Malaysia), CHLA levels increase during the winter-spring season (December to April) due to the strong northeasterly winds of the region and the occurrence of a coastal upwelling [24]. Strong seasonal variability has been reported in the Gulf of Alaska, with maximum values during winter-spring as a result of different combinations of environmental variables [25]. In the Bay of Bengal (India) strong seasonal variability in CHLA levels has been reported as a consequence of changes in the deep mixed layer, which in turn was associated with wind-driven mixing and the local atmospheric forcing [26].

The results presented here contribute to our understanding of the Bay of La Paz, a region considered as a hotspot of biodiversity and a region that is increasingly threatened by anthropogenic forcing, making it essential to determine the baseline conditions of the system in order to establish the repercussions of possible changes and their effects on the marine ecosystem, particularly on the phytoplankton community, a group of organisms that is essential for all marine trophic webs and is important in any marine ecosystem due to its contribution to mitigating climate change by reducing global $\mathrm{CO}_{2}$ levels.

\section{ACKNOWLEDGEMENTS}

The ship time of the research cruises on board the R/V El Puma was funded by UNAM. We appreciate the assistance of the crew members of the R/V "El Puma", as well as the participants of the research cruise. F. Sergio Castillo Sandoval provided technical support during the laboratory analyses. 


\section{REFERENCES}

[1] Davies, C.H., et al., 2018, "A database of chlorophyll-a in Australian waters". Scientific Data, 5, pp. 180018, http://dx.doi.org/10.1038/sdata.2018.18.

[2] Norton, A.J., Rayner, P.J., Koffi, E.N., and Scholze M., 2018, “Assimilating solar-induced chlorophyll fluorescence into the terrestrial biosphere model BETHY-SCOPE v1.0: model description and information content", Geoscientific Model Development, 11, pp. 1517-1536.

[3] Zhang, H, Qiu, Z., Sun, D., Wang, S., and He, Y., 2017, "Seasonal and Interannual Variability of Satellite-Derived Chlorophyll-a (2000-2012) in the Bohai Sea, China", Remote Sensing, 9, pp. 582, https://doi.org/10.3390/rs9060582.

[4] Durán-Campos, E., Monreal-Gómez, M.A., Salas de León, D.A., and CoriaMonter, E., 2019, "Impact of a dipole on the phytoplankton community in a semienclosed basin of the southern Gulf of California, Mexico", Oceanologia, 61, pp. 331-340. http://dx.doi.org/10.1016/j.oceano.2019.01.004.

[5] Arreguín-Sánchez, F., del Monte-Luna, P., Zetina-Rejón, M.J., and AlbañezLucero, O., 2017, "The Gulf of California large marine ecosystem: Fisheries and other natural resources", Environmental Development, 22, pp. 71-77, https://doi.org/10.1016/j.envdev.2017.03.002.

[6] Silverberg, N., Aguirre-Bahena, F., and Mucci, A., 2014, "Time-series measurements of settling particulate matter in Alfonso Basin, La Paz Bay, southwestern Gulf of California”, Continental Shelf Research, 84, pp. 169-187, https://doi.org/10.1016/j.csr.2014.05.005.

[7] Pérez-Cruz, L., 2006, "Climate and ocean variability during the middle and late Holocene recorder in laminated sediments from Alfonso Basin, Gulf of California, Mexico", Quaternary Research, 65, pp. 401-410, https://doi.org/10.1016/j.yqres.2006.02.003.

[8] Pérez-Cruz, L., 2013, "Hydrological changes and paleoproductivity in the Gulf of California during middle and late Holocene and their relationship with ITCZ and North American Monsoon variability", Quaternary Research, 79, pp. 138151, https://doi.org/10.1016/j.yqres.2012.11.007.

[9] Nava-Sánchez, E.H., Gorsline, D.S., and Molina-Cruz, A., 2001, “The Baja California peninsula borderland: structural and sedimentological characteristics", Sedimentary Geology, 144, pp. 63-82.

[10] Coria-Monter, E., Salas de León, D.A., Monreal-Gómez, M.A., and DuránCampos, E., 2019, "Internal waves in the Bay of La Paz, southern Gulf of California, Mexico", Vie et Milieu, 69 (2-3), pp. 115-122.

[11] Coria-Monter, E., Monreal-Gómez, M.A., Salas de León, D.A., and DuránCampos, E., 2017, "Wind driven nutrient and chlorophyll- $a$ enhancement at a cyclonic circulation in Bay of La Paz, Gulf of California, Mexico", Estuarine 
Coastal and Shelf Science, 196, pp. 290-300, http://dx.doi.org/10.1016/j.ecss.2017.07.010.

[12] Álvarez-Borrego, S., 2012, "Phytoplankton biomass and production in the Gulf of California: A review", Botanica Marina, 55, pp. 119-128, https://doi.org/10.1515/bot.2011.105.

[13] Martínez-López, A., Cervantes-Duarte R., Reyes-Salinas, A., and ValdezHolguín, J.E., 2001, "Cambio estacional de clorofila $a$ en la Bahía de La Paz, B.C.S., México”, Hidrobiológica, 11 (1), pp. 45-52. In Spanish

[14] Reyes-Salinas, A., Cervantes-Duarte, R., Morales-Pérez, R.A., and ValdezHolguín, J.E., 2003, "Variabilidad estacional de la productividad primaria y su relación con la estratificación vertical en la Bahía de la Paz, BCS", Hidrobiológica, 13(2), pp. 103-110. In Spanish.

[15] Coria-Monter, E., Monreal-Gómez, M.A., Salas de León, D.A., AldecoRamírez, J., and Merino-Ibarra, M., 2014, "Differential distribution of diatoms and dinoflagellates in a cyclonic eddy confined in the Bay of La Paz, Gulf of California", Journal of Geophysical Research Oceans, 119, pp. 6258-6268. http://dx.doi.org/10.1002/2014JC009916.

[16] Duran-Campos E., Salas de León D.A., Monreal-Gómez M.A., AldecoRamírez J., and Coria-Monter, E., 2015, "Differential zooplankton aggregation due to relative vorticity in a semi-enclosed bay", Estuarine Coastal and Shelf Science, 164, pp. 10-18, https://doi.org/10.1016/j.ecss.2015.06.030.

[17] Monreal-Gómez M.A., Molina-Cruz A., and Salas de León D.A., 2001, "Water masses and cyclonic circulation in Bay of La Paz, Gulf of California, during June 1998", Journal of Marine Systems, 30, pp. 305-315, https://doi.org/10.1016/S0924-7963(01)00064-1.

[18] Strickland, J.D.H., and Parsons, T.R., 1972, "A practical handbook of seawater analysis", Ottawa Fisheries Research Board of Canada, Bulletin 167, 293 p.

[19] Parsons, T.R., Maita, Y., and Lalli, C.M., 1984, "A manual of chemical and biological methods for seawater analysis", Pergamon Press, Oxford, 173 p.

[20] Coria-Monter, E., Monreal-Gómez, M.A., Salas de León, D.A., and DuránCampos, E., 2019, "Water masses and chlorophyll-a distribution in a semienclosed bay of the southern Gulf of California, Mexico, after the "Godzilla El Niño"”, Arabian Journal of Geosciences, 12, pp. 473, https://doi.org/10.1007/s12517-019-4636-1

[21] Lalli, C. M., and Parsons, T. R., 2006, "Biological Oceanography: An Introduction", Second edition, Oxford: Butterworth-Heinemann, 311 p.

[22] Mann, K. H., and Lazier, J. R. N., 2006, "Dynamics of Marine Ecosystems", Third edition. Blackwell Publishing. Oxford, UK, 489 p.

[23] Xu, Y., Chant, R., Gong, D., Castelao, R., Glenn, S., and Schofield, O., 2011, "Seasonal variability of chlorophyll a in the Mid-Atlantic Bight", Continental 
Shelf Research, 31(16), pp. 1640-1650, https://doi.org/10.1016/j.csr.2011.05.019.

[24] Abdul-Hadi, A., Mansor, S., Pradhan, B., and Tan, K., 2013, "Seasonal variability of chlorophyll-a and oceanographic conditions in Sabah waters in relation to Asian monsoon - a remote sensing study", Environmental Monitoring and Assessment, 185, pp. 3977-3991.

[25] Waite, J.N., and Mueter, F.J., 2013, "Spatial and temporal variability of chlorophyll-a concentrations in the coastal Gulf of Alaska, 1998-2011, using cloud-free reconstruction of Sea-WiFS and MODIS-Aqua data", Progress in Oceanography, 116, pp. 179-192, https://doi.org/10.1016/j.pocean.2013.07.006.

[26] Narvekar, J., and Prasanna Kumar, S., 2006, "Seasonal variability of the mixed layer in the central Bay of Bengal and associated changes in nutrients and chlorophyll”, Deep Sea Research I, 53(5), pp. 820-835. 
